\title{
A method for assessing volunteer bias and its application to a cardiovascular disease prevention programme involving physical activity
}

\author{
RICHARD D. REMINGTON \\ From the School of Public Health, University of Michigan \\ HENRY L. TAYLOR \\ From the Laboratory of Physiological Hygiene, University of Minnesota \\ E. R. BUSKIRK \\ From the Human Performance Laboratory, Pennsylvania State University
}

SUMMARY Studies of chronic disease may require long-term observation of volunteer participants. This is a characteristic of investigations of primary or secondary prevention of cardiovascular disease by increased level of physical activity. Activation of sedentary, middle-aged, high risk men requires a substantial personal commitment on their part to a long-term programme. Because of self-selection, individuals who volunteer for such programmes cannot be assumed to be representative of the populations from which they come. To the best of our knowledge, there has been no systematic investigation of such self-selection based upon a study designed for that purpose. We found little consistent tendency for volunteering behaviour to be associated with serum cholesterol, blood pressure, relative weight, level of activity at work, or Type A behaviour variables.

The general design of this study has been described before (Taylor et al., 1973). Middle-aged American men in two communities were asked to volunteer for progressively more demanding commitments, ranging from taking part in a brief telephone interview to adhering to a regular prescribed programme of physical activity involving attendance at several scheduled training sessions a week for more than a year. At the end of each stage, participants were asked to volunteer for the next stage. Those who did so can therefore be compared with those who did not with respect to any variable measured at the current or earlier stages of the study. The Figure illustrates the study design.

Men in the study populations were sampled, and individuals who were not selected into the sample provided no data for the study. Sampled men were asked to complete a telephone interview; some of them refused and, again, provided no study data. Men who completed the telephone interview were invited to attend a risk classification examination; some of them refused, but they can be compared with examination attenders with respect to any variable measured during the telephone interview.

Those who attended the risk classification examination were divided into 'high risk' and 'low risk' men on the basis of their serum cholesterol levels, blood pressure, and smoking status. This division was not voluntary, and therefore involved no self-selection. The object of the study was to examine men at relatively high risk of developing coronary heart disease. Low risk men were not invited to participate further. High risk men, on the other hand, were invited to attend a recruitment meeting where many aspects of coronary heart disease and its relationship to risk factors were explained. At this meeting, men were told that they were at relatively high risk. Again, some men attended the recruitment meeting and some did not. These two groups can be compared with respect to variables measured both at the risk classification examination and during the telephone interview.

At the end of the recruitment meeting, men were asked to volunteer for the long-term programme of physical training. Some men volunteered and some did not, again providing a comparison of variables 


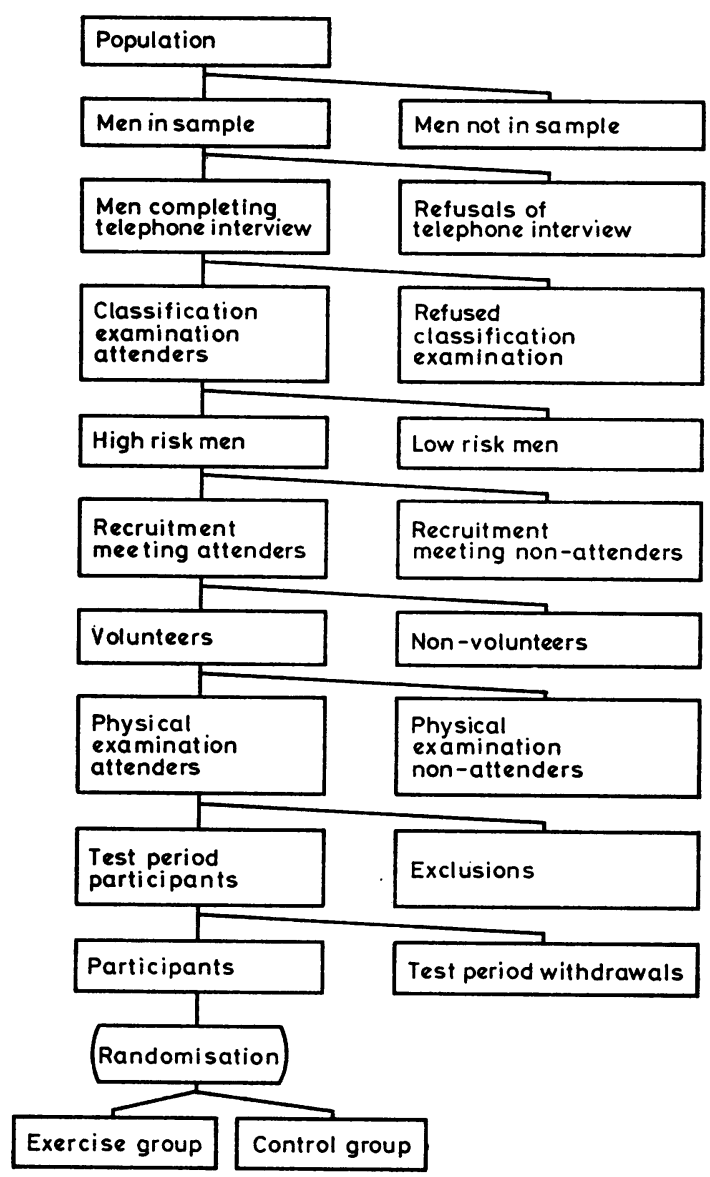

Figure Study design

measured earlier. The men who did volunteer were asked to attend a detailed physical examination; some attended, some did not. Of the men who did attend, some were excluded as the result of medical findings that made it inadvisable for them to continue with the programme. The remaining men undertook a four-week test period, designed to identify those whose attendance at the obligatory three sessions a week would be sufficiently irregular to make them poor study participants. These sessions involved tests of strength, agility, balance, and flexibility; they made low demands on capacity for endurance. The balance of the required time was taken up by anthropometric measurements and by the completion of questionnaires. Those men who withdrew - that is, those who did not faithfully attend sessions during the test period - can be compared with those who participated throughout the test period, and could finally be randomised into 'exercise' and 'control' groups for the intensive, long-term study.

Data from the two study centres participating in this investigation are reported here. In Minneapolis, Minnesota, an area-stratified probability sample was selected of men aged 40-59 living in two major residential areas. The sampling frame consisted of telephone directories, because the initial contact with potential participants was to be made by telephone. In a preliminary canvass of the two areas, it was discovered that more than $95 \%$ of dwellings had telephones, thus reducing to an acceptable level the possible bias due to excluding residences without telephones. In Minneapolis, the study design was the same as that shown in the Figure.

At Pennsylvania State University, a similar design was used. All male faculty and staff members aged 40-59 were invited to participate. Here, however, the risk classification and detailed physical examinations were combined.

Table 1 Number of participants at various stages by institution

\begin{tabular}{|c|c|c|c|c|}
\hline \multirow{4}{*}{$\begin{array}{l}\text { Study stages } \\
\text { Men contacted by telephone } \\
\text { Men completing telephone } \\
\text { interview } \\
\text { Men completing classification } \\
\text { examination } \\
\text { High risk men } \\
\text { Entered test period } \\
\text { Randomised participants } \\
\text { Exercise }\end{array}$} & \multicolumn{2}{|c|}{$\begin{array}{l}\text { Minnesota } \\
\text { No. } \quad \%\end{array}$} & \multicolumn{2}{|c|}{$\begin{array}{l}\text { Penn State } \\
\text { No. } \quad \%\end{array}$} \\
\hline & 1528 & $100 \cdot 0$ & 1623 & $100 \cdot 0$ \\
\hline & 1331 & $87 \cdot 1$ & 1581 & $97 \cdot 4$ \\
\hline & $\begin{array}{l}978 \\
493 \\
137 \\
115\end{array}$ & $\begin{array}{r}64 \cdot 0 \\
32 \cdot 3 \\
9 \cdot 0 \\
7 \cdot 5 \\
57 \\
58\end{array}$ & $\begin{array}{r}1376 \\
383 \\
189 \\
171\end{array}$ & $\begin{array}{l}84.8 \\
23.6 \\
11.6 \\
10.5\end{array}$ \\
\hline
\end{tabular}

Table 1 illustrates the numbers and percentages of participants at various study stages by institution. A smaller percentage of men $(87 \cdot 1 \%$ compared with $97.4 \%$ ) completed the telephone interview at Minnesota than at Pennsylvania State. Perhaps this was because the Minnesota men were a sample from a general population, whereas the Pennsylvania State study group were employees of the University under whose auspices the investigation was being conducted. Similar factors might be responsible for the higher percentage of drop-outs between the telephone interview and the completion of the classification examination at Minnesota. Somewhat different criteria were used for defining 'high risk' in the two studies, and this is why a larger percentage of men were identified as 'at high risk' in Minnesota.

\section{Results}

Tables 2 and 3 illustrate the pattern of analysis used in this study for the single variable, serum cholesterol $(\mathrm{mg} / 100 \mathrm{ml})$, in Minnesota high risk men. The men who refused to attend the recruitment meeting had 
Table 2 Participation status by serum cholesterol level $(\mathrm{mg} / 100 \mathrm{ml})$, Minnesota high risk men

\begin{tabular}{|c|c|c|c|c|c|c|c|c|}
\hline \multirow{3}{*}{ Category } & \multicolumn{8}{|c|}{ Serum cholesterol level } \\
\hline & \multirow[b]{2}{*}{ Mean } & \multicolumn{7}{|c|}{ Number of men } \\
\hline & & $<245$ & $245-259$ & $260-274$ & $275-289$ & $290-304$ & $>305$ & Total \\
\hline $\begin{array}{l}\text { 1. Randomised men } \\
\text { 2. Test period withdrawals } \\
\text { 3. Medical exclusions } \\
\text { 4. Physical examination non-attenders } \\
\text { 5. Non-volunteers } \\
\text { 6. Recruitment mtg refusals } \\
\text { All high risk men }\end{array}$ & $\begin{array}{l}267 \\
250 \\
265 \\
273 \\
269 \\
280 \\
271\end{array}$ & $\begin{array}{r}21 \\
9 \\
10 \\
5 \\
30 \\
21 \\
96\end{array}$ & $\begin{array}{r}31 \\
7 \\
8 \\
11 \\
33 \\
17 \\
107\end{array}$ & $\begin{array}{r}23 \\
3 \\
8 \\
3 \\
26 \\
29 \\
92\end{array}$ & $\begin{array}{r}22 \\
1 \\
9 \\
5 \\
19 \\
30 \\
86\end{array}$ & $\begin{array}{r}7 \\
1 \\
3 \\
8 \\
5 \\
22 \\
46\end{array}$ & $\begin{array}{r}11 \\
1 \\
2 \\
4 \\
22 \\
26 \\
66\end{array}$ & $\begin{array}{r}115 \\
22 \\
40 \\
36 \\
135 \\
145 \\
493\end{array}$ \\
\hline
\end{tabular}

a somewhat higher than average mean $(280 \mathrm{mg} /$ $100 \mathrm{ml}$ ), while the 22 men who withdrew during the test period had a somewhat lower level $(250 \mathrm{mg} /$ $100 \mathrm{ml}$ ). Three separate analyses were completed for association in contingency tables such as that of Table 2: the conventional Pearson $\chi^{2}$ statistic; the $\chi^{2}$ statistic based on the generalised likelihood ratio (-2 1n $\lambda$ ) (Mood and Graybill, 1963); and the Goodman-Kruskal G (gamma) measure of association (Goodman and Kruskal, 1954; 1959; 1963).

Contingency tables were partitioned in order to assess conditions leading to the overall association between participation status and the response variable. These partitions were formed by taking the top row in a contingency table and comparing it with the aggregated table formed by summing the frequencies in the remaining rows; then taking the second row and comparing its frequencies with the sum of entries in succeeding rows, etc. Such a partition results in an orthogonal division of the total association present in the table, and permits assessment of individual contributions to the association. However, only the generalised likelihood ratio statistic is exactly additive under such a partition, in the sense that the sum of the individual components is equal to the overall statistic calculated from the full, non-partitioned table, except for rounding error.

Table 3 Participation status by serum cholesterol level ( $\mathrm{mg} / 100 \mathrm{ml})$, Minnesota high risk men: Contingency table analysis

\begin{tabular}{|c|c|c|c|c|}
\hline Categories & $\begin{array}{l}\text { Statistics } \\
\text { Mean }\end{array}$ & $x^{2}$ & $-2 \ln \lambda$ & $\boldsymbol{G}$ \\
\hline \multirow{6}{*}{$\begin{array}{l}1 \dagger \\
2-6 \\
2-6 \\
3-6 \\
3 \\
4-6 \\
4 \\
5-6 \\
5 \\
6 \\
\text { All }\end{array}$} & \multirow{6}{*}{$\begin{array}{l}267 \\
272 \\
250 \\
273 \\
265 \\
274 \\
273 \\
275 \\
269 \\
280 \\
271\end{array}$} & $5 \cdot 74$ & $5 \cdot 94$ & 0.09 \\
\hline & & $11 \cdot 57^{*}$ & $11 \cdot 78^{*}$ & $0 \cdot 49 * *$ \\
\hline & & $5 \cdot 16$ & $6 \cdot 03$ & $0 \cdot 20$ \\
\hline & & $10 \cdot 73$ & $10 \cdot 10$ & 0.00 \\
\hline & & $20.05^{* *}$ & $20 \cdot 99^{* *}$ & $0 \cdot 26^{* *}$ \\
\hline & & $53 \cdot 54^{* *}$ & $54 \cdot 85^{* *}$ & $0 \cdot 17^{* *}$ \\
\hline
\end{tabular}

$* 0.01<\mathrm{P}<0.05$

+Participation categories as defined in Table 2
Results of the analysis and partition are given in Table 3 for serum cholesterol level among Minnesota high risk men. In Table 3, the row labelled 'All', under the heading 'Categories', gives the results for the three tests of association and indicates that by each of the three criteria there are statistically significant differences in the overall Table. That is, the distribution of serum cholesterol is not constant across the six rows of the full contingency table. To determine the source of the association, we refer to the partition given in the Table. Serum cholesterol distribution for randomised men (category 1) is not significantly different from that for all remaining high risk men $(267 \mathrm{mg} / 100 \mathrm{ml}$ versus $272 \mathrm{mg} / 100 \mathrm{ml}$ ). However, the 22 men who withdrew from the study during the test period (category 2) had a serum cholesterol distribution different from the men who withdrew at an earlier point in the stated design (mean $250 \mathrm{mg} / 100 \mathrm{ml}$ versus $273 \mathrm{mg} / 100 \mathrm{ml}$ ). Furthermore, those men who refused to attend the recruitment meeting (category 6) are significantly different in serum cholesterol distribution from those who refused to volunteer (means $280 \mathrm{mg}$ / $100 \mathrm{ml}$ versus $269 \mathrm{mg} / 100 \mathrm{ml}$ ).

In Table 3 the assessment of significance by the three statistical procedures used is similar. This holds throughout the analysis of data from this study. In the condensed presentation of additional results, significance will be described on the basis of the generalised likelihood ratio statistic, for several reasons: the partition of association based on this statistic is exact; the requirements for size of frequencies needed are less restrictive for the likelihood ratio statistic than for the Pearson $\chi^{2}$; and, as noted, the assessment of significance is not substantially different using the three methods.

Table 4 summarises the results of analyses for high risk men at Minnesota and Pennsylvania State for serum cholesterol, systolic and diastolic blood pressure, and relative weight. As noted earlier, the determination of risk status was primarily based upon serum cholesterol and, to a lesser degree, upon elevated blood pressure. For that reason, an artificial and planned high association 
Table 4 Risk variable means by participation categories, high risk men

\begin{tabular}{|c|c|c|c|c|c|c|c|}
\hline \multirow[b]{2}{*}{ Variable } & \multicolumn{7}{|c|}{ Participation category } \\
\hline & $1+$ & 2 & 3 & 4 & 5 & 6 & $A l l$ \\
\hline $\begin{array}{l}\text { Serum cholesterol (mg/100 ml) Minnesota } \\
\text { Serum cholesterol (mg/100 ml) Penn State } \\
\text { Systolic blood pressure (mm Hg) Minnesota } \\
\text { Systolic blood pressure (mm Hg) Penn State } \\
\text { Diastolic blood pressure (mm Hg) Minnesota } \\
\text { Diastolic blood pressure (mm Hg) Penn State } \\
\text { Relative weight (\%) Minnesota } \\
\text { Relative weight (\%) Penn State } \\
\text { No. of men: Minnesota } \\
\text { No. of men: Penn State }\end{array}$ & $\begin{array}{l}267 \\
269 \\
134^{*} \\
134 \\
83 \\
85 \\
116 \\
117 \\
115 \\
170\end{array}$ & $\begin{array}{l}250^{*} \\
263 \\
144 \\
134 \\
86 \\
85 \\
121^{*} \\
117 \\
22 \\
60\end{array}$ & $\begin{array}{l}\frac{265}{143^{*}} \\
\frac{88^{*}}{117} \\
\frac{40}{0}\end{array}$ & $\begin{array}{l}\frac{273}{134} \\
\frac{85}{119 *} \\
\frac{36}{0}\end{array}$ & $\begin{array}{l}269 * * \\
265 \\
135 \\
134 \\
84 \\
86 \\
116 \\
113^{*} \\
135 \\
52 \\
\end{array}$ & $\begin{array}{r}280 \\
267 \\
136 \\
137 \\
85 \\
85 \\
117 \\
117 \\
145+t \\
91\end{array}$ & $\begin{array}{l}271^{* *} \\
267 \\
136 * * \\
135 \\
84 \\
85 \\
117 * \\
117 \\
493 \\
373\end{array}$ \\
\hline
\end{tabular}

would result if low risk men were included in the analysis. In studying Table 4, it is also important to recall that the process at Pennsylvania State involved fewer stages than that at Minnesota; hence fewer participation categories are available in the Pennsylvania State data.

We see in the first row of Table 4 a summary of the results illustrated in detail in Tables 2 and 3 -namely, the significant association $(P<0.01)$ of participation category with serum cholesterol when the entire set of data is included; the reduced serum cholesterol level among men withdrawing during the test period compared with men withdrawing earlier $(0.01<P<0.05)$; and the higher serum cholesterol level of men refusing attendance at the recruitment meeting $(P<0.01)$. This last significant association is reflected by the indicated significance in category 5 , which is a comparison between non-volunteers and men refusing to attend the recruitment meeting. Finally, the conclusion that randomised men are not significantly different from the aggregated men refusing participation earlier in the staged sequence is reflected by the lack of significance of the entry for Minnesota serum cholesterol in column 1 of Table 4. The serum cholesterol distributions for the Pennsylvania State data show no statistically significant effect of selection by participation status.

Systolic blood pressure distributions at Minnesota indicate an overall association with participation status that is highly significant $(P<0.01)$. Randomised men have a slightly lower mean systolic blood pressure than men dropping out earlier $(0.01<\mathbf{P}<$ 0.05 ), whereas the systolic blood pressure of medical exclusions appears to be somewhat higher than that of men refusing participation earlier $(0.01<\mathbf{P}<$ 0.05). Again, systolic blood pressure distributions among different participation categories in the Pennsylvania State data show no statistically significant differences, and the means of the distributions reflect this finding.
Diastolic blood pressure distributions reveal few differences at either place of study, the only exception being a slightly elevated diastolic pressure among medical exclusions at Minnesota. This is, perhaps, due to the systematic exclusion of a few men with substantially elevated blood pressure. Modest differences only in relative weight appear at the two study sites.

On-job and off-job physical activity levels, using the methods of Shapiro et al. (1965) were analysed in a similar manner. There was no evidence of selection for participation on the basis of on-job physical activity at either place. For off-job activity, however, randomised men at both Minnesota and Pennsylvania State showed a higher $(0.01<\mathbf{P}<$ $0.05)$ frequency of more active men than were present in the overall group $(54 \%$ versus $41 \%$ at Minnesota, and $59 \%$ versus $52 \%$ at Pennyslvania State). Thus, high risk men who were habitually more active in their leisure time tended more often to proceed through the stages of this investigation at both institutions and become randomised participants than did their less active colleagues.

Analysis of cigarette smoking status, conducted in a similar manner, suggested that randomised men at Minnesota were lower in frequency of current cigarette smoking than men who did not proceed through the study to the stage of randomisation (39\% versus $49 \%$ ). Furthermore, men withdrawing during the test period showed a somewhat higher frequency of cigarette use than the total group $(57 \%$ versus $48 \%$ ). Men at Pennyslvania State refusing to attend the recruitment meeting showed a substantially higher frequency of cigarette use than the overall group $(66 \%$ versus $34 \%$ ). Because of the similarities in outcomes at the two centres, the somewhat compressed design at Pennyslvania State, and the fact that somewhat heavier use was made of cigarette smoking status in defining high risk men at Pennyslvania State, detailed results will be presented only for the Minnesota group. 
Table 5 Percentage of current cigarette smokers by participation category, Minnesota

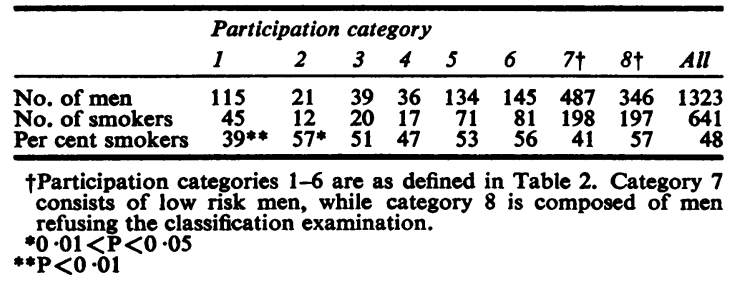

Table 5 gives the findings of the partitioned contingency table analysis, again based upon the generalised likelihood ratio statistic, but this time including high risk men and classification examination refusals.

\section{Discussion}

The results of this study suggest that a design explicitly providing for systematic assessment of volunteer status may be useful in long-term studies of chronic disease. Such a design can permit comparisons of participants and non-participants at each of several study stages. From these results, it appears that cigarette smokers volunteer for such investigations less frequently than their non-smoking counterparts.

Analyses similar to those reported here were completed on a number of other variables. These included positive family history of heart disease, attitudes and beliefs about the relationship between exercise and heart attack, and some questions designed to elicit Type A overt behaviour pattern (Rosenman et al., 1964; Zyzanski and Jenkins, 1970; Jenkins, 1971). There were only slight differences in the frequency of positive family history at Minnesota, but at Pennyslvania State a somewhat greater number of men withdrawing during the test period reported some history of heart attack in the immediate family $(53 \%$ versus $35 \%$ overall). With respect to perceived relationship between exercise and risk of heart attack, Minnesota men refusing to attend the physical examination apparently less often felt that exercise is related to heart attacks than did men dropping out earlier $(65 \%$ versus $79 \%$ ). At both institutions, the percentages of men eventually randomised who believed that a relationship exists between exercise and heart attack was slightly higher than in the overall group of men asked the question. However, at neither institution were randomised men significantly different in this respect from men dropping out earlier in the sequential procedure.

At both institutions, there was a significantly higher frequency of married men eventually ran- domised than dropping out earlier $(95 \%$ versus $92 \%$ at Minnesota and $97 \%$ versus $94 \%$ at Pennyslvania State). The Minnesota difference reached significance at the $5 \%$ level, but at Pennyslvania State it fell just short of significance.

The sequence of questions designed to elicit Type A behaviour pattern was: (1) 'Would you say that you are the hard-driving, aggressive type of person, or are you more average, or maybe even easy-going?'; (2) 'Do you mind if you have to wait, say you have an appointment with someone and he makes you wait . . . or if you have to wait in line?'; and (3) 'Do you often have the feeling that time is passing all too quickly each day to get done all that needs to be done?'

The answers to the first two questions showed no significant variation in distribution by participation status. These questions were asked only at the Minnesota telephone interview, and thus similar information is not available for Pennsylvania State. The third question on time urgency showed some variation in the Minnesota data, but of a complex pattern difficult to interpret. In summary, we found little evidence that behaviour patterns assessed in this interview were related to participation status.

\section{Conclusions}

We found little consistent tendency for volunteering behaviour to be associated with serum cholesterol, blood pressure, relative weight, on-job activity level, or behavioural variables of the Type A pattern. Cigarette smokers tended to volunteer less frequently than non-smokers, and men whose off-job activity level was habitually higher tended to volunteer more often. There was some suggestion that volunteers more often felt that exercise was related to the risk of heart attack than did nonvolunteers. There was no clear relationship between volunteering and a family history of heart attacks. Finally, married men tended to volunteer more often than unmarried men.

This investigation was supported in part by contracts from the Heart Disease Control Programme of the United States Public Health Service.

We thank H. Blackburn, E. S. Fetcher, B. Hamrell, and J. Alexander of the University of Minnesota; J. Skinner, W. C. Nicholas, O. Bar-Or, J. Kollias, and J. Mendez of the Pennsylvania State University; M. A. Schork and M. Vaage of the Co-ordinating Centre, and S. Fox III, W. Haskell, and F. Heinzelmann of the Heart Disease Control Programme. A committee chaired by $\mathbf{H}$. Blackburn and including A. Kattus, H. Hellerstein, and R. Bruce developed the exclusion criteria and safety precautions. 
J. Stamler and F. Epstein served on the Steering Committee.

Reprints from Richard D. Remington, School of Public Health, University of Michigan, 109, S. Observatory, Ann Arbor, MI 48109, USA.

\section{References}

Goodman, L. A., and Kruskal, W. H. (1954). Measures of association for cross classifications. Journal of the American Statistical Association, 49, 732-764.

Goodman, L. A., and Kruskal, W. H. (1959). Measures of association for cross classification. II: Further discussions and references. Journal of the American Statistical Association, 54, 123-163.

Goodman, L. A., and Kruskal, W. H. (1963). Measures of association for cross classification. III: Approximate sampling theory. Journal of the American Statistical Association, 58, 310-364.

Jenkins, C. D. (1971). Psychologic and social precursors of coronary heart disease. New England Journal of Medicine, 284, 244-255; 307-318.
Mood, A. M., and Graybill, F. A. (1963). Introduction to the Theory of Statistics. Second edition, pp. 312-314. McGraw Hill: New York.

Rosenman, R. H., Friedman, M., Straus, R., Wurn, M., Kositchek, R., Hahn, W., and Werthessen, N. (1964). A predictive study of coronary heart disease. The Western Collaborative Group Study. Journal of the American Medical Association, 189, 103-110.

Shapiro, S., Weinblatt, E., Frank, C. W., and Sager, R. V. (1965). The H.I.P. study of incidence and prognosis of coronary heart disease. Preliminary findings on incidence of myocardial infarction and angina. Journal of Chronic Diseases, 18, 527-558.

Taylor, H. L., Buskirk, E. R., and Remington, R. D. (1973). Exercise in controlled trials of the prevention of coronary heart disease. Federation Proceedings, 32, 1623-1627.

Zyzanski, S. J., and Jenkins, C. D. (1970). Basic dimensions within the coronary-prone behaviour pattern. Journal of Chronic Diseases, 22, 781-795. 